\title{
Avaliação do Padrão de Fermentação de Silagens Elaboradas com Espécies Forrageiras do Estrato Herbáceo da Caatinga Nordestina ${ }^{1}$
}

\author{
Márcia Maria Cândido da Silva ${ }^{2}$, Adriana Guim ${ }^{3}$, Edgard Cavalcanti Pimenta Filho ${ }^{4}$, Genaro \\ Viana Dornellas ${ }^{5}$, Manoel Francisco de Sousa ${ }^{6}$, Merilândia Vieira de Figueiredo ${ }^{7}$
}

\begin{abstract}
RESUMO - Objetivou-se, com o presente estudo, acompanhar o padrão de fermentação de silagens elaboradas com plantas constituintes do estrato herbáceo da Caatinga em dois sítios ecológicos (SE-1 e SE-2) do Cariri paraibano. A identificação das espécies presentes no estrato foi realizada por intermédio da classificação das plantas. Para avaliação do padrão de fermentação, as plantas amostradas foram picadas em máquina forrageira e, após homogeneização, parte foi exposta ao sol para efeito do emurchecimento. Em amostras frescas e emurchecidas, determinaram-se o poder tampão (PT) e o teor de carboidratos solúveis em água (CHOs) na MS. Em mini-silos de PVC, confeccionaram-se 48 silagens para cada sítio ecológico, os quais foram abertos após $3,7,14,21,28$ e 35 dias de armazenamento, para avaliação das variações em matéria seca (MS), pH e nitrogênio amoniacal $\left(\mathrm{N}-\mathrm{NH}_{3} / \mathrm{N}\right.$ total). Realizaram-se análises de variância e regressão para as características estudadas. Efeito significativo do emurchecimento sobre todas as características foi observado nas silagens do SE-1. A análise de regressão estimou equações quadráticas para MS e pH apenas para as silagens frescas. Para as silagens do SE-2, o emurchecimento exerceu influência sobre a MS, mas a análise de regressão não estimou equações para esta característica. Quanto ao $\mathrm{pH}$, foram estimadas equações: linear para as silagens frescas e quadrática para as emurchecidas. Equações lineares foram obtidas para o $\mathrm{N}^{-\mathrm{NH}_{3}}$ para as duas silagens estudadas tanto nos dois sítios ecológicos. As silagens do SE-1 não apresentaram padrão de fermentação satisfatório, o que provavelmente se deu em função do elevado teor de umidade das silagens bem como a participação de leguminosas nas mesmas. As silagens emurchecidas do SE-2 apresentaram padrão de fermentação satisfatório.
\end{abstract}

Palavras-chave: estrato herbáceo, fermentação, semi-árido, silagem

\section{Evaluation of Standard Fermentation of Silages Elaborated with Forage Species of the Herbaceous Stratum of Brazilian Northeast Region}

\begin{abstract}
The present study aimed to observe silages fermentation pattern elaborated with plant samples from the herbaceous stratum of two ecological ranches (SE-1 and SE-2) in the Caatinga area in the state of Paraíba, Brazil. The species presented in the stratum were identified by the classification of plants. To evaluate fermentation pattern, the herbaceous stratum were pricked in forage machine and, after homogenization, a part of it was exposed to sun in order to lose excess of water (wilted). In fresh and wilted samples, buffering capacity (BC) and soluble carbohydrate content in the DM were determined. In small PVC silos, 48 silages were made for each ecological ranch, which were opened after 3,7,14,21,28 and 35 stocked days to evaluate dry matters (DM) variations, $\mathrm{pH}$ and $\mathrm{N}-\mathrm{NH}_{3}$. Variance and regression analyses were made for the studied characteristics. Significant wilted effect was observed in SE-1 silages. Regression analyses stimulated quadratic equations for DM and $\mathrm{pH}$ just for fresh silages. For SE-2 silages, the wilted exercised influence on the $\mathrm{DM}$, but the regression analyses did not estimate equations for this characteristic. Related to $\mathrm{pH}$, these equations were estimated: linear for fresh silages and quadratic for the wilted. Linear equations were obtained to the $\mathrm{N}-\mathrm{NH}_{3}$ for both silages that were studied in the ranches. SE-1 silages did not present satisfactory fermentation, that probably happened because of the silage high humidity contents, as well as legumes participation. The wilted SE-2 silages presented satisfactory fermentation pattern.
\end{abstract}

Key Words: herbaceous stratum, fermentation, semi-arid, silage

\footnotetext{
1 Parte do trabalho de Dissertação apresentada à UFPB pelo primeiro autor, para obtenção do título de Mestre em Zootecnia

${ }^{2}$ Doutoranda em Zootecnia, UFV, Viçosa, MG. CEP: 36520-000 E.mail: marciacandido@vicosa.ufv.br

3 Professora Orientadora DZ/UFRPE. E.mail: aguim@ufrpe.br

${ }^{4}$ Professor Dr. DZ/CCA/UFPB. Areia - PB. CEP: 58397-000. E.mail: edgard@cca.ufpb.br

${ }^{5}$ Professor DF/CCA/UFPB. Areia - PB. CEP: 58397-000.

${ }_{6}^{6}$ Mestre em Zootecnia, CNPA/EMBRAPA, Campina Grande, PB. E.mail: manoel@cnpa.embrapa.br

${ }^{7}$ Aluna do curso de Zootecnia, Bolsista PIBIC/CNPq/UFPB. E.mail: mvdefigueiredo@yahoo.com.br
} 


\section{Introdução}

A Caatinga nordestina é de grande importância para a sobrevivência dos produtores de baixa renda que dependem da pecuária bovina, ovina e/ou caprina. A alimentação destes ruminantes é um dos maiores problemas enfrentados pelos pecuaristas, em função, principalmente, das constantes estiagens que assolam a região, associadas ao desconhecimento de tecnologias que explorem a disponibilidade das diversas espécies que constituem a comunidade vegetal da caatinga (Lima et al., 1987).

A região Nordeste caracteriza-se por apresentar duas estações definidas ao longo do ano: uma seca e outra chuvosa. No período das águas, a caatinga rebrota e faz surgir o estrato herbáceo, que apresenta grande diversidade de plantas nativas e exóticas naturalizadas, a maioria com características forrageiras, as quais são aproveitadas pelos animais através do pastejo direto. No entanto, como este estrato surge de forma efêmera, os animais não conseguem consumi-lo totalmente, o que acaba gerando excedente forrageiro. O aproveitamento deste excedente herbáceo pode ser uma alternativa viável para o fornecimento de alimentos de baixo custo no período de estiagem, sendo necessário lançar mão de recursos que promovam a sua conservação.

Entre os meios usuais de conservação de excedentes forrageiros, a fenação é a técnica mais comumente utilizada na região Nordeste, talvez pela aparente simplicidade do processo. A ensilagem, apesar de não ser uma técnica muito difundida, é extremamente favorável, pois, além de conservar o alimento, permite preservar o que há de mais valioso no período seco, a água.

A qualidade da silagem produzida depende de propriedades intrínsecas do próprio alimento e das condições ambientais proporcionadas no interior do silo, como vedação das superfícies, exclusão do ar, compactação da massa, tamanho de partícula, entre outros (Tosi et al., 1999). A espécie forrageira, o teor de matéria seca, a idade da planta e sua composição química são alguns fatores intrínsecos ao alimento que irão influenciar o produto final (Silveira, 1988).

As principais características que determinam o padrão de fermentação, durante a ensilagem, envolvem a interação dos fatores: teor de matéria seca, carboidratos solúveis e poder tampão da planta (Wilkinson, 1998). Esses fatores podem influenciar negativamente o processo fermentativo, impedindo o rápido decréscimo do $\mathrm{pH}$, favorecendo assim fermentações secundárias indesejáveis (Woolford, citado por Ítavo et al., 1998).

Como a umidade excessiva parece impedir a fermentação adequada no silo, o emurchecimento surge como alternativa para melhorar o padrão de fermentação nos silos (Alkmim Filho et al., 1998).

É grande o número de publicações enfatizando que milho e sorgo são as forrageiras mais adequadas para a elaboração de boas silagens. Entretanto, poucas são as observações relativas à ensilagem de outras espécies forrageiras tropicais. Este enfoque ainda é mais restrito quando do uso de plantas herbáceas da caatinga nordestina.

Assim, objetiva-se com este trabalho obter informações sobre o padrão de fermentação de silagens elaboradas com o estrato herbáceo da Caatinga, em dois sítios ecológicos, com e sem a prática do emurchecimento.

\section{Material e Métodos}

O experimento, nas etapas de colheita, redução das partículas, enchimento e vedação dos silos, foi conduzido nos sítios ecológicos das fazendas Riacho da Cobra (SE-1) e Pedra Rica (SE-2), localizadas nos municípios de Gurjão e Barra de Santana, respectivamente, ambas inseridas no Cariri paraibano.

A confecção das silagens ocorreu nos meses de março e maio de 1999 para o SE-1 e SE-2, respectivamente, utilizando-se o estrato herbáceo (cortado rente ao solo) disponível em cada sítio. Para o reconhecimento das plantas que constituíam o estrato herbáceo, confeccionaram-se herbários, cuja classificação se baseou em seu nome vulgar e científico (Tabelas 1 e 2).

A abertura dos silos, bem como as análises laboratoriais, foi realizada no Centro de Ciências Agrárias, Campus III da Universidade Federal da Paraíba, localizado no município de Areia - PB, Brejo Paraibano.

O SE-1 apresentou grande participação de dicotiledôneas herbáceas, não se observando, no entanto, predominância de nenhuma espécie. Todas, aparentemente, encontravam-se em proporções semelhantes. Já no SE-2, apesar da presença de dicotiledôneas herbáceas, notou-se maior participação de gramíneas.

Devido à grande variedade de espécies em cada sítio ecológico, a determinação da idade das plantas ao corte foi descrita, de maneira geral, de acordo com o estádio vegetativo aproximado das espécies encon- 
tradas em maior proporção. Dessa forma, nos dois sítios ecológicos, a maioria das plantas encontrava-se no estádio de florescimento e frutificação, à exceção de algumas leguminosas arbustivas, como a jureminha e a algaroba (SE-1), que se encontravam no estádio inicial de crescimento.

Nos dois sítios ecológicos, o material, após coleta, foi picado em máquina forrageira convencional, com redução de partículas entre 2,0 e $5,0 \mathrm{~cm}$, apresentando irregularidades, devido a características inerentes ao material que, por vezes, apresentava resistência ao processo de picagem e, por vezes, continha muita umidade, proporcionando maceramento bastante acentuado. Cabe ressaltar que o material do sítio 2 (Fazenda Pedra Rica) apresentou maiores irregularidades.

Parte do material coletado, imediatamente após a redução de tamanho, foi exposta ao sol, por aproximadamente cinco horas, para emurchecimento. A composição bromatológica dos materiais fresco e emurchecido está apresentada na Tabela 3.

Armazenou-se o material picado em silos experimentais confeccionados com tubos de PVC, com $50 \mathrm{~cm}$ de altura, $15 \mathrm{~cm}$ de diâmetro e volume calculado em

Tabela 1 - Relação das espécies do estrato herbáceo da Fazenda Riacho da Cobra (SE - 1), no momento da ensilagem

Table 1 - Relation of the species of the herbaceous stratum of the "Riacho da Cobra" farm (ecological site 1), at ensilage time

\begin{tabular}{lll}
\hline Nome vulgar & $\begin{array}{l}\text { Nome científico } \\
\text { Usual name }\end{array}$ & Scientific name \\
\hline 01 & Algaroba & Prosopis juliflora \\
02 & Arranca estrepe & Heliotropium indicum \\
03 & Belota roxa & Cholis inflata \\
04 & Bredo & Amaranthus deflexus \\
05 & Búffel & Cenchrus ciliaris \\
06 & Capim mão-de-sapo & Dactyloterrium aegyptium \\
07 & Capim milhã & Panicum sp. \\
08 & Capim milho de cabra & Eragrostis sp. \\
09 & Capim pega-pinto & Boerhaavia diffusa \\
10 & Camapú & Physalis angulata \\
11 & Cordão de S. Francisco & Leonotis nepetifolia \\
12 & Jitirana & Ipomoea aff.hederacea \\
13 & Jureminha & Desmanthus virgatus \\
14 & Malva branca & Sida cordifolia \\
15 & Mata pasto & Senna obtusifolia \\
16 & Maxixe & Cucumis anguria \\
17 & Melancia & Citrilus vulgaris \\
18 & Relógio & Sida aff. Glaziovii \\
\hline
\end{tabular}

$0,009 \mathrm{~m}^{3}$. Durante o enchimento dos mesmos, efetuaram-se pesagens para proporcionar a mesma pressão de compactação em todos os silos $\left(500 \mathrm{~kg} / \mathrm{m}^{3}\right)$, totalizando aproximadamente $5,5 \mathrm{~kg}$ de forragem $/$ silo. Para vedação utilizaram-se sacos plásticos e fita adesiva. Após vedação, os silos foram mantidos em temperatura ambiente até as datas de aberturas.

No momento da abertura dos silos, realizaram-se observações quanto às características organolépticas de amostras das partes superior, central e inferior. Da parte central dos silos retirou-se uma alíquota, a qual foi levada à estufa com circulação forçada a $60 \pm 5^{\circ} \mathrm{C}$ para determinação do poder tampão (PT) e dos teores de carboidratos solúveis em água (CHOs), segundo as metodologias descritas por Playne \& McDonald (1966) e Balwani, citado por Guim (1997), respectivamente. Das amostras obtidas na última abertura (35 dias de fermentação) também foram determinados os teores de matéria seca (MS), proteína bruta (PB), fibra em detergente neutro (FDN), fibra em detergente ácido (FDA), cinzas (C) e matéria orgânica (MO), segundo as metodologias descritas por Silva (1990).

De outra alíquota retirada da parte central do silo

Tabela 2 - Relação das espécies do estrato herbáceo da Fazenda Pedra Rica (SE - 2), no momento da ensilagem

Table 2 - Relation of the species of the herbaceous stratum of the "Pedra Rica" farm (ecological site 2), at ensilage time

\begin{tabular}{lll}
\hline Nome vulgar & $\begin{array}{l}\text { Nome científico } \\
\text { Usual name }\end{array}$ & Scientific name \\
\hline 1 & & Alternanthera sp. \\
2 & & Wissadula cv.subpeltata \\
3 & Albina & Turnera indica \\
4 & Bananinha & Indigofera cv. Suffruticora \\
5 & Beldruéga & Portulaca oleracea \\
6 & Belota roxa & Cholis inflata \\
7 & Bredo & Portulaca halimoides \\
8 & Bromil & Polygalla violacea \\
9 & Búffel & Cenchrus ciliaris \\
10 & Capim belota & Chloris polydactylla \\
11 & Capim mão-de-sapo & Dactyloterrium aegyptium \\
12 & Capimmilhã & Panicum sp. \\
13 & Capim milho de cabra & Eragrostis sp. \\
14 & Capim mimoso & Digitaria sp. \\
15 & Capim pega-pinto & Boerhaavia diffusa \\
16 & Feijão de rola & Macroptilium sp. \\
17 & Mata pasto de pêlo & Senna pilifera \\
18 & Milhã & Brachiaria pantaginea \\
19 & Relógio & Sida aff. Glaziovii \\
20 & Relógio & Sida rhombifolia \\
21 & Vassourinha & Sidastrum paniculatum \\
22 & Vassourinha de botão & Spermacae verticillata \\
\hline & &
\end{tabular}


extraiu-se o suco, por intermédio de uma prensa mecânica, para determinação do $\mathrm{N}-\mathrm{NH}_{3}$, segundo a metodologia descrita por Preston (1986), e valores do pH com uso de potenciômetro.

Utilizou-se o delineamento experimental inteiramente casualizado em parcelas subdividas, em que se avaliaram dois tipos de materiais ensilados (estrato herbáceo verde e emurchecido), que foram alocados nas parcelas, e seis tempos de vedação dos silos (3, $7,14,21,28$ e 35 dias), alocados nas subparcelas, com quatro repetições, totalizando 48 unidades experimentais (silos). A análise estatística foi realizada pelo SAEG (UFV, 1997). Partindo-se dos resultados analíticos, foram estimadas equações de regressão para as características avaliadas em função dos tempos de fermentação.

Vale salientar que as análises para caracterização do processo de ensilagem, em cada um dos dois sítios ecológicos, foram realizadas separadamente, sem, no entanto, compará-las entre si.

\section{Resultados e Discussão}

Padrão de fermentação da forragem colhida no sítio ecológico 1

O estrato herbáceo que constituiu as silagens do sítio ecológico 1 (SE-1) apresentou valores médios de 47,2 eq. mg HCl/ 100 g MS e 5,48\% para o poder tampão e carboidratos solúveis em água na MS, respectivamente. Provavelmente, este fato foi de- corrente da maior presença de dicotiledôneas herbáceas (incluindo leguminosas) que apresentam elevado poder tampão (McDonald, 1981; Lavezzo, 1985) e baixos teores de carboidratos solúveis (Tosi et al., 1975; Morais et al., 1998).

De acordo com López (1975), a quantidade inicial de carboidratos solúveis na forrageira a ser ensilada contribui para rápida fermentação com produção de ácidos orgânicos, principalmente ácido lático. Com respeito ao poder tampão das forrageiras, Lavezzo (1985) menciona que o problema de ensilar forrageiras com elevado poder tampão resulta da necessidade de aumento no teor de ácido lático, de modo a reduzir o $\mathrm{pH}$ para valores adequados.

Com o emurchecimento, observou-se leve decréscimo no poder tampão (37,3 eq. $\mathrm{mg} \mathrm{HCl} / 100 \mathrm{~g}$ MS) e no teor de carboidratos solúveis $(4,74 \%) \mathrm{em}$ relação ao estrato herbáceo fresco. Decréscimos nos valores do poder tampão também foram observados por Berto \& Mühlbach (1997), por ação do emurchecimento. Da mesma forma, Gutierrez \& De Faria (1976) e Rangrab et al. (2000) observaram redução nos teores de carboidratos solúveis, quando da utilização desta técnica.

Na Figura 1, são apresentadas as tendências para as variações de $\mathrm{MS}, \mathrm{pH}$ e N-NH $\mathrm{N}_{3}$ ao longo do processo de fermentação. Observa-se que as colunas representam os teores de MS e pH do material fresco (EF) e emurchecido (EE) no momento da ensilagem.

Os valores de $\mathrm{pH}$, assim como os teores de MS e

\begin{tabular}{|c|c|c|c|c|}
\hline $\begin{array}{c}\text { Table } 3 \text { - } \begin{array}{c}\text { Chemical composition } \\
(E S-1 \text { and ES-2) }\end{array} \\
\end{array}$ & ect cut & $d$ herbaceous & atum in th & ecological sites \\
\hline \multirow{2}{*}{$\begin{array}{l}\text { Composição } \\
\text { Composition }\end{array}$} & \multicolumn{2}{|c|}{$\begin{array}{c}\mathrm{SE}-1 \\
\text { Ecological site } 1\end{array}$} & \multicolumn{2}{|c|}{$\begin{array}{c}\mathrm{SE}-2 \\
\text { Ecological site } 2\end{array}$} \\
\hline & $\begin{array}{l}\text { Fresco } \\
\text { Direct cut }\end{array}$ & $\begin{array}{c}\text { Emurchecido } \\
\text { Wilted }\end{array}$ & $\begin{array}{l}\text { Fresco } \\
\text { Direct cut }\end{array}$ & $\begin{array}{c}\text { Emurchecido } \\
\text { Wilted }\end{array}$ \\
\hline Matéria seca (\%) & 21,0 & 23,8 & 26,1 & 33,9 \\
\hline $\begin{array}{l}\text { Dry matter (\%) } \\
\text { Proteína bruta (\% MS) }\end{array}$ & 16,3 & 16,1 & 8,7 & 9,4 \\
\hline $\begin{array}{l}\text { Crude protein }(\% D M) \\
\text { Matéria orgânica }(\% \mathrm{MS}) \\
\text { Organic matter }(\% \text { DM) }\end{array}$ & 84,2 & 84,5 & 88,5 & 88,8 \\
\hline $\begin{array}{l}\text { Cinzas }(\% \mathrm{MS}) \\
\text { Ash }(\% D M)\end{array}$ & 15,8 & 15,5 & 11,5 & 11,2 \\
\hline $\begin{array}{l}\text { Fibra detergente neutro (\% MS) } \\
\text { Neutral detergent fiber }(\% D M)\end{array}$ & 39,3 & 47,4 & 67,9 & 64,9 \\
\hline $\begin{array}{l}\text { Fibra detergente ácido (\% MS) } \\
\text { Acid detergent fiber }(\% \text { DM) }\end{array}$ & 28,3 & 34,4 & 39,2 & 39,1 \\
\hline
\end{tabular}


(a)

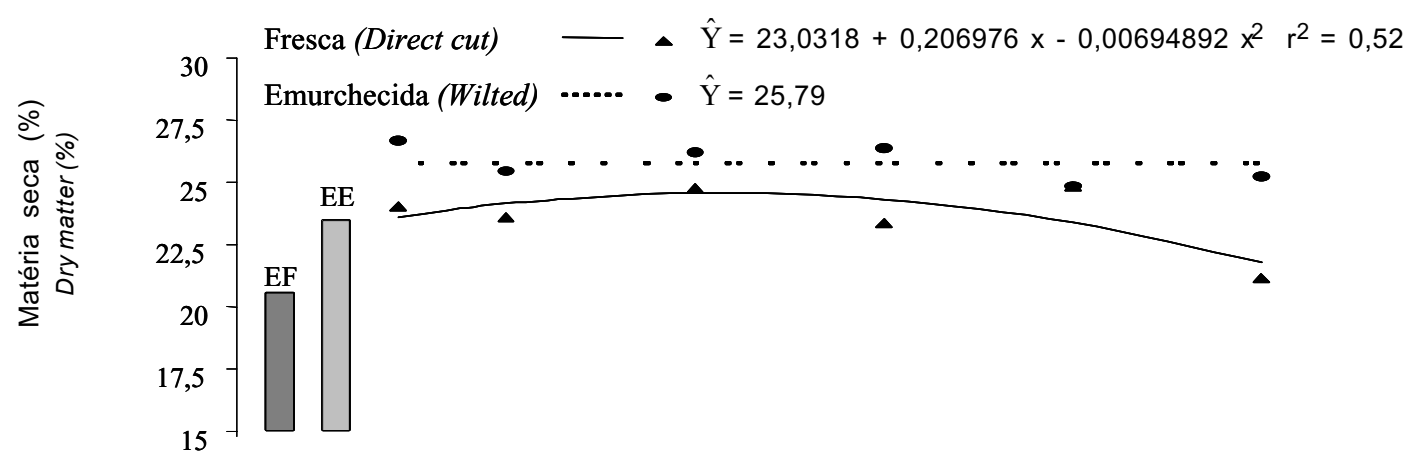

(b)

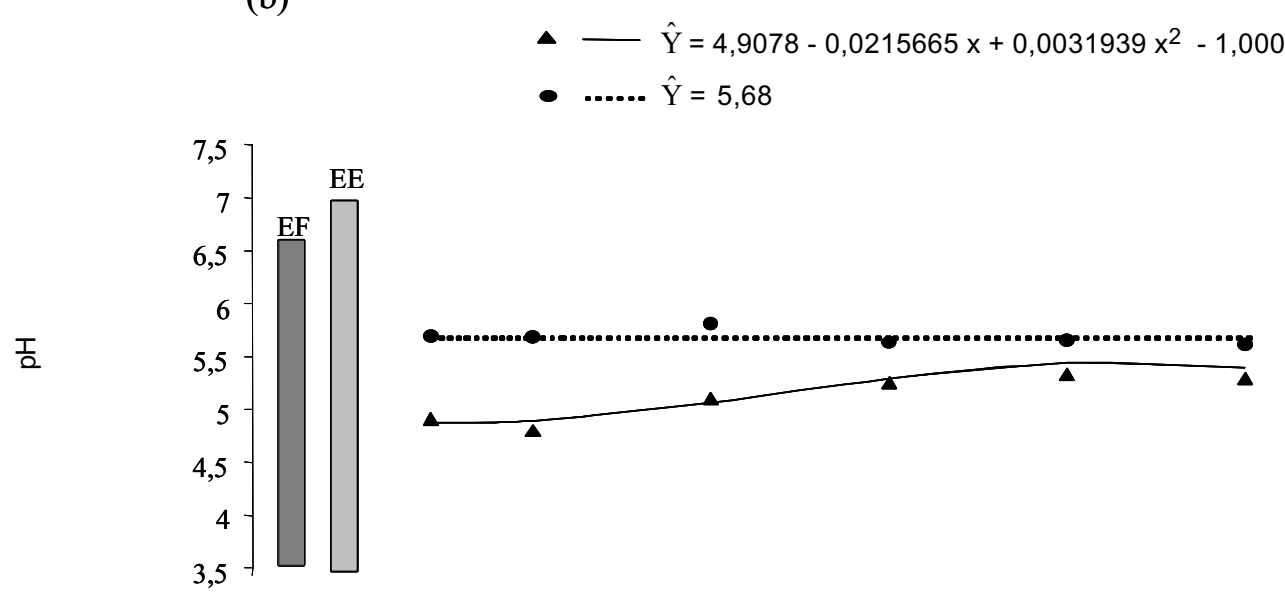

(c)

- — $\hat{\mathrm{Y}}=6,76204+0,293961 \times r^{2}=0,86$

- …... $\hat{Y}=4,74333+0,628681 \times r^{2}=0,89$

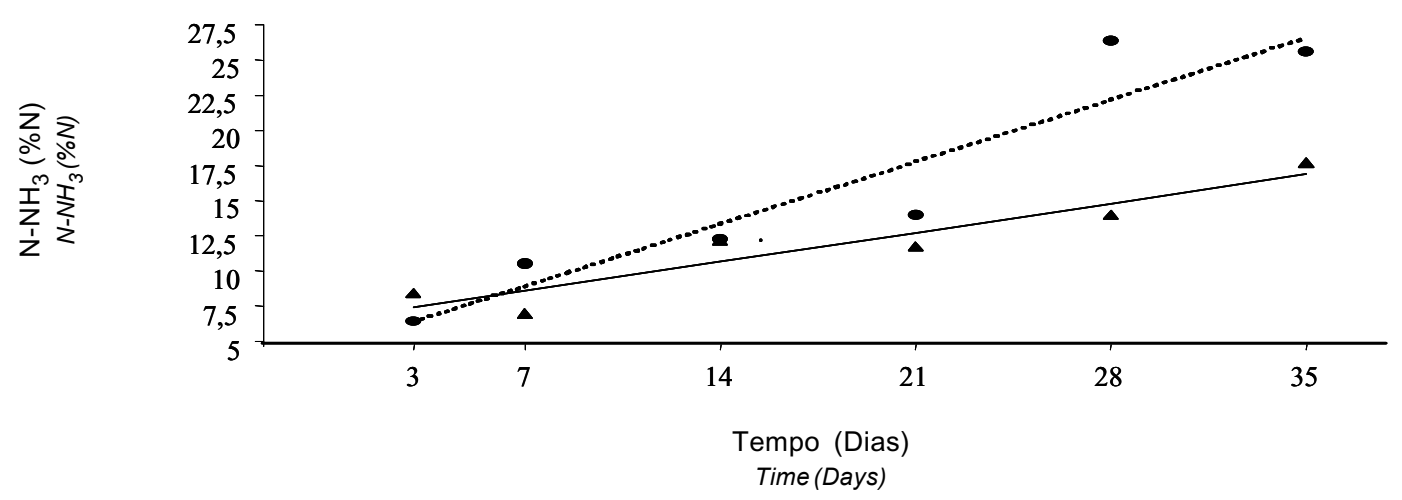

Figura 1 - Padrão de fermentação da forragem colhida no sítio ecológico 1 (SE-1), em função do tempo de fermentação. Valores médios de $\mathrm{MS}$ (a), $\mathrm{pH}$ (b) e N-NH $\mathrm{N}_{3}$ (c) das silagens frescas $(-)$ e emurchecidas $(---)$.

Figure 1 - Fermentation standard of the forage harvested in the ecological site 1 (ES-1), in function of time of fermentation. Mean of $\mathrm{DM}$ (a), $\mathrm{pH}$ (b) and $\mathrm{N}-\mathrm{NH}_{3}$ (c) of the silages direct cut (- ) and wilted (---).

EF - Estrato fresco (Direct cut stratum).

EE - Estrato emurchecido (Wilted stratum). 
$\mathrm{N}-\mathrm{NH}_{3}$ das silagens, variaram $(\mathrm{P}<0,05)$ em resposta ao emurchecimento, mas a magnitude dos efeitos variou com o tempo de fermentação. Assim, a análise de regressão apresentou significância para os teores de MS e pH apenas para as silagens frescas, estimando equações quadrática e cúbica, respectivamente. Com relação aos teores de $\mathrm{N}^{-\mathrm{NH}_{3}}$, foram estimadas equações de regressão lineares, tanto para as silagens frescas quanto para as emurchecidas.

O comportamento da MS demonstrado pela curva para o material fresco revela oscilações ao longo do tempo de fermentação. A curva atingiu o valor máximo por volta do 15 o dia, estimando-se teor de $25,9 \%$ MS. A partir deste momento, tendeu a sofrer decréscimos, à medida que se aumentou o tempo de fermentação. Estas oscilações podem ser atribuídas à variabilidade do material ensilado, associado ao alto teor de umidade do mesmo.

Mesmo havendo diferença significativa entre os materiais fresco e emurchecido, o emurchecimento não foi suficiente para elevar os teores de MS até níveis considerados ótimos para um padrão de boa fermentação, que, segundo Silveira (1988), deve estar entre 30 e $40 \%$ MS, embora silagens de híbridos de sorgo com teor de matéria seca entre 25 e $29 \%$ tenham sido consideradas de boa qualidade pelo autor. Baixos teores de MS de silagens podem influenciar a fermentação, favorecendo o desenvolvimento de bactérias do gênero Clostridium, afetando a qualidade da silagem (McDonald, 1981).

Apesar de não ter sido realizada análise estatística, observa-se na Figura 1 que os valores de MS determinados em amostras dos estratos fresco e emurchecido foram inferiores aos teores médios obtidos nas silagens (20,98 e 23,78\%, respectivamente). Este aumento no teor de MS observado nas silagens em relação aos estratos (colunas) pode ter sido decorrente das perdas de efluentes das silagens, que está de acordo com os resultados obtidos por Borges et al. (1997).

Quanto ao $\mathrm{pH}$, o emurchecimento favoreceu o aumento dos seus valores nas silagens, apresentando valor médio de 5,68, que é considerado elevado para promover silagens de boa qualidade (Silveira, 1988). No entanto, considerando a heterogeneidade do material utilizado nas silagens, principalmente com a participação de leguminosas, este nível de $\mathrm{pH}$ situa-se dentro da faixa aceitável para silagens elaboradas com leguminosas (Tosi et al., 1975). Jones et al. (1971) relataram que o aumento do teor de matéria seca das silagens tem ocasionado acréscimo no valor de $\mathrm{pH}$.

Embora tenha se estimado equação significativa, os valores de $\mathrm{pH}$ para as silagens frescas também não foram satisfatórios para proporcionar boa fermentação. Nesta variável também foi observado que, mesmo com o elevado poder tampão apresentado pelos estratos fresco e emurchecido (47,2 e 37,3 eq. mg HCl/ $100 \mathrm{~g}$ MS, respectivamente), foi possível rápido decréscimo do $\mathrm{pH}$ porém não a níveis inferiores a 4,5.

Para os valores de $\mathrm{N}_{-} \mathrm{NH}_{3}$, os modelos lineares estimados para as silagens denotam que os teores de nitrogênio amoniacal aumentaram, em função do tempo de fermentação. As silagens frescas, embora tenham apresentado valores inferiores às silagens emurchecidas, não apresentaram valores inferiores a $10 \%$, denotando que, provavelmente, ocorreu proteólise considerável (McDonald, 1981; AFRC, 1987; Ítavo et al., 1998; Brito et al., 1998).

Com base nos resultados encontrados e representados na Figura 1, pode-se inferir que as silagens confeccionadas com estrato fresco e emurchecido do sítio ecológico 1 não apresentaram padrão de fermentação adequados para obtenção de silagens de boa qualidade.

O tempo de exposição ao sol para o emurchecimento não foi suficiente para elevar os teores de MS para os níveis entre 30 e $40 \%$, o que pode ter contribuído negativamente para o seu objetivo, já que mesmo com acréscimo significativo da MS não houve queda acentuada do $\mathrm{pH}$, e elevou, consideravelmente, os teores de nitrogênio amoniacal. A composição bromatológica das silagens aos 35 dias de fermentação é apresentada na Tabela 4.

$\mathrm{O}$ elevado teor protéico encontrado nas silagens frescas e emurchecidas é atribuído à maior participação de dicotiledôneas (incluindo leguminosas) no estrato herbáceo deste sítio ecológico. Vários trabalhos têm sido realizados incluindo leguminosas forrageiras como aditivos de silagem com o objetivo de elevar o teor protéico das mesmas (Obeid et al., 1986; López \& Mühlbach, 1991; Eichelberger et al., 1997).

De maneira geral, 75 a 90\% do nitrogênio total de uma forragem fresca está presente na proteína, o restante do NNP consiste em aminoácidos livres e amidas com pequenas quantidades de aminas, nucleotídeos, clorofila, peptídeos de baixo peso molecular e aminoácidos ligados a compostos nãoprotéicos. A quantidade de $\mathrm{N}-\mathrm{NH}_{3}$ livre corresponde, normalmente, a menos de $1 \%$ do nitrogênio total

R. Bras. Zootec., v.33, n.1, p.87-96, 2004 
(McDonald et al., 1981). Durante o processo de fermentação, há redução do nitrogênio protéico e aumento do não protéico (Danley e Vetter, 1973), que deve ser levado em consideração, já que os teores de $\mathrm{N} \mathrm{NH}_{3}$ nestas silagens foram consideráveis (Figura 1).

É válido salientar que, mesmo com o padrão descrito anteriormente, estas silagens apresentaram características organolépticas satisfatórias e apenas nas partes superiores e inferiores dos silos foi notada a presença de fungos. Além disso, não foi constatado aumento de temperatura no interior dos silos. Isto evidencia que, provavelmente, poderão ser obtidas silagens de boa qualidade elaboradas com estratos herbáceos de composição semelhante ao SE-1, desde que se aumente o tempo de emurchecimento e utilizem aditivos ricos em açúcares para favorecer o aumento de substrato para bactérias produtoras do ácido lático.

Padrão de fermentação da forragem colhida no sítio ecológico 2

O estrato herbáceo fresco que constituiu as silagens do sítio ecológico 2 (SE-2) apresentou valores de 15,78 eq. $\mathrm{mg} \mathrm{HCl} / 100 \mathrm{~g} \mathrm{MS} \mathrm{e} \mathrm{4,55 \%} \mathrm{para} \mathrm{o} \mathrm{poder} \mathrm{tampão} \mathrm{e}$ carboidratos solúveis, respectivamente. Este fato era esperado, já que neste estrato a participação de gramíneas era visivelmente superior às dicotiledôneas herbáceas. As gramíneas possuem poder tampão inferior aos das leguminosas (Lavezzo, 1985).

$\mathrm{O}$ emurchecimento acarretou leve acréscimo no poder tampão (18,6 eq. $\mathrm{mg} \mathrm{HCl} / 100 \mathrm{~g} \mathrm{MS})$ e ligeiro decréscimo no teor de carboidratos solúveis $(4,48 \%)$. Resultados semelhantes foram observados por Rangrab et al. (2000).

Houve diferença significativa $(\mathrm{P}<0,05)$ entre as silagens estudadas para os teores de $\mathrm{MS}, \mathrm{pH}$ e $\mathrm{N}-\mathrm{NH}_{3}$. Apenas para a variável MS não foram estimadas equações de regressão.

$\mathrm{Na}$ Figura 2, as colunas representam os teores de MS e pH do material fresco (EF) e emurchecido (EE) no momento da ensilagem. Mesmo sem compará-los estatisticamente, é possível notar que ambos apresentaram teores de MS superiores $(26,12$ e $33,92 \% \mathrm{MS})$ aos teores médios obtidos nas silagens frescas e emurchecidas, que foram de 24,97 e $28,76 \%$, respectivamente.

O emurchecimento foi suficiente para elevar os teores de MS da forragem para valores próximos aos níveis considerados ótimos para promover boa fermentação.
Quanto aos valores de $\mathrm{pH}$, as silagens frescas apresentaram tendência linear decrescente (Figura 2), em que, com o aumento do tempo de fermentação (dia), ocorreu decréscimo do pH de 0,013882 . Já as silagens emurchecidas apresentaram tendência quadrática, com o ponto mínimo de 4,13 obtido aos 25,2 dias de fermentação, tendendo a elevar-se a partir deste ponto.

Pode-se considerar que os valores obtidos para as silagens elaboradas com o material deste sítio ecológico apresentaram valores muito próximos aos considerados ideais $(4,0-4,2)$ por Silveira (1988). Este fato provavelmente é decorrente da maior proporção de gramíneas observadas no material, por ocasião da ensilagem.

Ainda na Figura 2, as colunas representam os valores de $\mathrm{pH}$ no momento da ensilagem para o material fresco (EF) e emurchecido (EE). Verifica-se redução acentuada do pH no $3 \underline{0}$ dia após a ensilagem, provavelmente em função da maior participação de gramíneas na composição deste estrato.

Com relação ao $\mathrm{N}^{-\mathrm{NH}_{3}}$, os modelos lineares estimados para as silagens denotam que, à medida que se aumentou o tempo de fermentação, elevaram-se também os teores de nitrogênio amoniacal. Para as silagens frescas, para cada unidade (dia), há aumento de $0,103 \%$ no teor de $\mathrm{N}-\mathrm{NH}_{3}$. Já para as emurchecidas o acréscimo é da ordem de $0,178 \%$ no teor de $\mathrm{N}-\mathrm{NH}_{3}$.

Tabela 4 - Composição bromatológica das silagens do SE-1, frescas (SF) e emurchecidas (SE) após 35 dias de armazenamento

Table 4 - Chemical composition of the silages of the ecological site 1 , direct cut and wilted silages after 35 storage days

\begin{tabular}{|c|c|c|c|c|c|c|}
\hline \multirow{4}{*}{$\begin{array}{l}\text { Silagem } \\
\text { Silage }\end{array}$} & \multirow{4}{*}{$\begin{array}{c}\mathrm{MS}^{1} \\
D M \%\end{array}$} & \multicolumn{5}{|c|}{$\begin{array}{l}\text { Composição } \\
\text { Composition } \\
\end{array}$} \\
\hline & & $\mathrm{PB}^{2}$ & $\mathrm{MO}^{3}$ & $C^{4}$ & $\mathrm{FDN}^{5}$ & $\mathrm{FDA}^{6}$ \\
\hline & & $C P$ & $O M$ & Ash & $N D F$ & $A D F$ \\
\hline & & & & $\begin{array}{l}M S \\
D M\end{array}$ & & \\
\hline Fresca & 21,2 & 15,0 & 82,9 & 17,1 & 39,8 & 29,2 \\
\hline $\begin{array}{l}\text { Direct cut silage } \\
\text { Emurchecida } \\
\text { Wilted silage }\end{array}$ & 25,2 & 15,4 & 83,0 & 17,0 & 43,9 & 33,2 \\
\hline
\end{tabular}

${ }^{1}$ Matéria seca (dry matter).

2 Proteína bruta (crude protein).

3 Matéria orgânica (organic matter).

${ }^{4}$ Cinzas (ash)

${ }^{5}$ Fibra em detergente neutro (neutral detergent fiber).

${ }^{6}$ Fibra em detergente ácido (acid detergent fiber). 
(a)

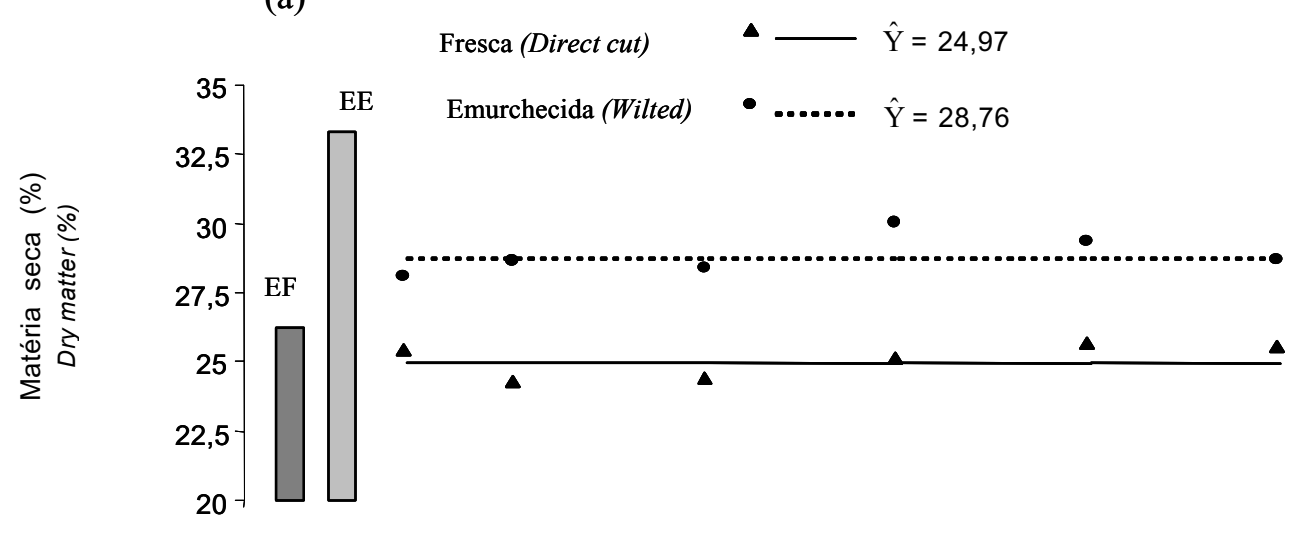

(b)

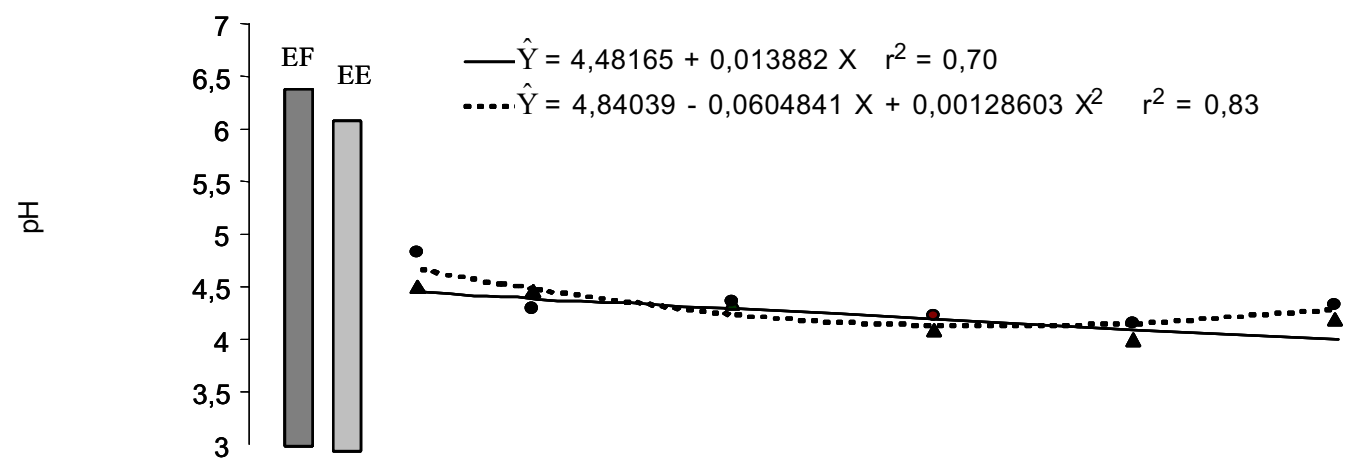

(c) $\hat{Y}=5,80339+0,103099 \times r^{2}=0,54$

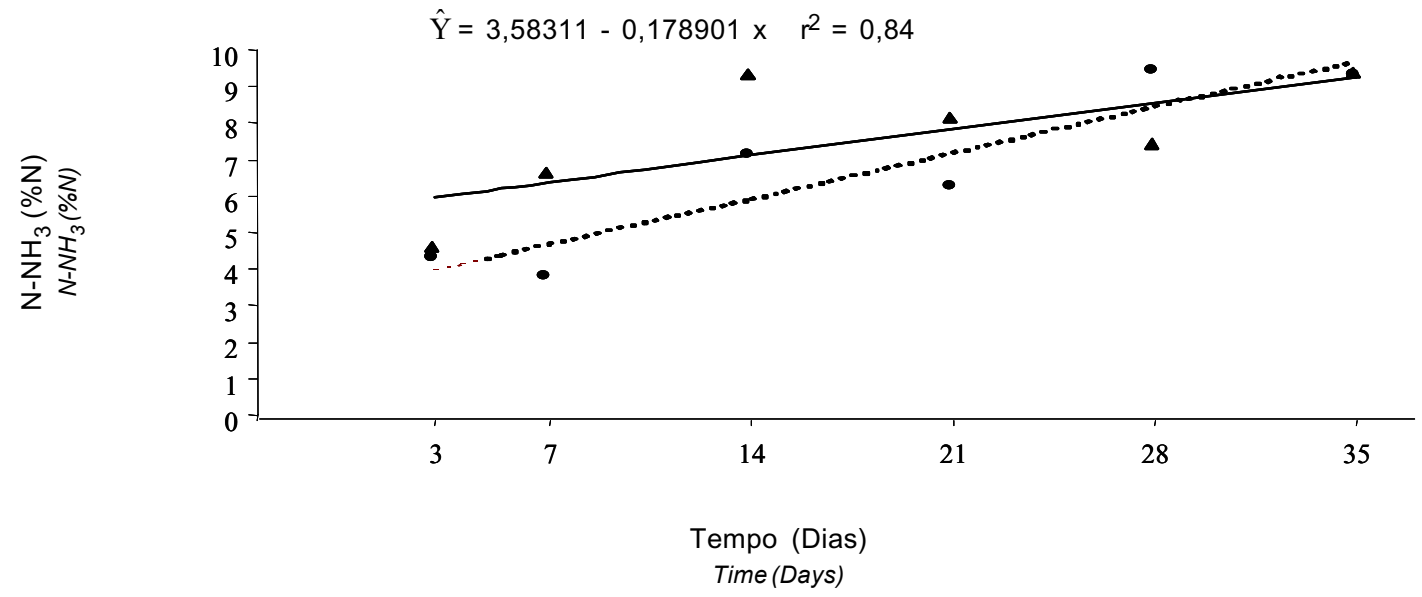

Figura 2 - Padrão de fermentação da forragem colhida no sítio ecológico 2 (SE-2) em função do tempo de fermentação. Valores médios de $\mathrm{MS}$ (a), pH (b) e N-NH ${ }_{3}$ (c) das silagens frescas $(-)$ e emurchecidas $(--)$.

Figure 2 - Fermentation standard of the forage harvested in the ecological site 2 (ES-2) in function of time of fermentation. Mean of $\mathrm{DM}(\mathrm{a}), \mathrm{pH}$ (b) and $\mathrm{N}^{-\mathrm{NH}_{3}}$ (c) of the silages direct cut ( - ) and wilted (- - $)$.

EF - Estrato fresco (Direct cut stratum).

EE - Estrato emurchecido (Wilted stratum). 
A análise de regressão, embora tenha estimado uma equação linear para as silagens frescas, apresentou coeficiente de correlação muito baixo, onde é possível perceber que a curva não representou bem o processo de ensilagem deste material, ficando muito distantes dos pontos reais, embora os mesmos tenham sido crescentes. As duas silagens, no entanto, apresentaram teores considerados dentro do limite para boa fermentação, onde nenhuma delas mostrou valores superiores a $10 \%$, que é considerado por McDonald (1981), AFRC (1987) e Brito et al. (1998) como indicativo de acentuada proteólise. Ítavo et al. (1998), entretanto, consideram que a proteólise é intensa a partir de $8 \%$ de $\mathrm{N}-\mathrm{NH}_{3}$.

As silagens deste sítio ecológico, apesar de terem mantido tendência linear para os teores de $\mathrm{N}^{-\mathrm{NH}_{3}}$, apresentaram, de maneira geral, boa caracterização de fermentação, já que não houve perda de MS e foi possível obter decréscimos desejáveis nos valores de $\mathrm{pH}$ ao longo do processo fermentativo.

A composição bromatológica das silagens frescas e emurchecidas do SE - 2 são apresentadas na Tabela 5, na qual pode ser observado que as silagens tenderam a manter composição próxima ao material original (Tabela 3 ).

Assim como aconteceu para as silagens do SE-1, as silagens do SE-2 também apresentaram características organolépticas satisfatórias. A presença de fungos foi mais notada na parte superior, que pode ser atribuída à maior aeração, em virtude da maior dificuldade de obtenção de boa compactação desta camada, principalmente na silagem emurchecida. A menor compactação conferida às silagens emurchecidas se deu pela dificuldade inerente ao próprio material, que ficou bastante seco, e, principalmente, à ineficácia da máquina forrageira para reduzir a forragem a partículas uniformemente pequenas. No entanto, durante os tempos de aberturas dos silos, também não foram constatados aumentos de temperatura no interior dos mesmos.

De modo geral, para os dois sítios ecológicos, em virtude da heterogeneidade de plantas neste complexo vegetal com vistas a melhores resultados em trabalhos posteriores, sugere-se aumentar o número de repetições por tratamento, bem como estimar, por intermédio de metodologias apropriadas, o percentual de participação de cada espécie, empregar aditivos e aumentar o tempo de emurchecimento, principalmente em sítios ecológicos que apresentem abundância de dicotiledôneas herbáceas.
Tabela 5 - Composição bromatológica das silagens do SE-2, frescas (SF) e emurchecidas (SE) após 35 dias de armazenamento

Table 5 - Chemical composition of the silages of the ecological site 2, direct cut and wilted silages after 35 storage days

\begin{tabular}{lccccccc}
\hline & & \multicolumn{5}{c}{$\begin{array}{c}\text { Composição } \\
\text { Composition }\end{array}$} \\
\cline { 3 - 7 } Silagem & $\mathrm{MS}^{1}$ & $\mathrm{~PB}^{2}$ & $\mathrm{MO}^{3}$ & $\mathrm{C}^{4}$ & $\mathrm{FDN}^{5}$ & $\mathrm{FDA}^{6}$ \\
& $D M \%$ & $C P$ & $O M$ & $A s h$ & $N D F$ & $A D F$ \\
\cline { 3 - 7 } & & \multicolumn{5}{c}{$\% \mathrm{MS}$} \\
$\%$ & & & & \\
\hline Fresca & 25,5 & 9,1 & 88,2 & 11,7 & 60,0 & 38,8 \\
$\begin{array}{l}\text { Direct cut silage } \\
\text { Emurchecida }\end{array}$ & 28,6 & 9,0 & 87,6 & 12,4 & 60,7 & 38,7 \\
Wilted silage & & & & & & \\
\hline
\end{tabular}

${ }^{1}$ Matéria seca (dry matter).

2 Proteína bruta (crude protein).

3 Matéria orgânica (organic matter).

${ }^{4}$ Cinzas (ash).

${ }^{5}$ Fibra em detergente neutro (neutral detergent fiber).

${ }^{6}$ Fibra em detergente ácido (acid detergent fiber).

\section{Conclusões}

O estrato herbáceo colhido no sítio ecológico 1 caracterizou-se por maior quantidade de dicotiledôneas herbáceas (incluindo leguminosas) e apresentou elevado poder tampão. Em relação à caracterização do sítio ecológico 2, a participação das gramíneas foi considerável e o poder tampão, baixo. Os teores de carboidratos solúveis das plantas colhidas nos dois sítios ecológicos foram relativamente baixos.

As silagens frescas e emurchecidas confeccionadas com as espécies presentes no estrato herbáceo do sítio ecológico 1 não apresentaram padrão de fermentação satisfatório. O tempo de emurchecimento não foi suficiente para reduzir o teor de umidade das plantas, a fim de propiciar boas condições de fermentação das silagens.

As silagens elaboradas com as espécies do estrato herbáceo do sítio ecológico 2 apresentaram padrão de fermentação satisfatório.

\section{Literatura Citada}

AGRICULTURAL AND FOOD RESEARCH COUNCIL AFRC. Technical Committee on Responses to Nutrients Report. Number 2. Characterisation of feedstuffs nitrogen. Nutrition Abstracts and Reviews (Series B), v.57, n.12, p.713-736, 1987. 
ALKMIM FILHO, J.F.; GONÇALVES, L.C.; BORGES, I. et al. Valor nutritivo de silagens de híbridos de Sorghum bicolor $\mathrm{x}$ Sorghum sudanenses submetidas a pré-secagens. I- $\mathrm{pH}$, Nitrogênio amoniacal e proteína. In: REUNIÃO ANUAL DA SOCIEDADE BRASILEIRA DE ZOOTECNIA, 35., 1998, Botucatu. Anais ... Botucatu: Sociedade Brasileira de Zootecnia, 1998. p.743-745.

BERTO, J.L.; MÜHLBACH, P.R.F. Silagem de aveia preta no estádio vegetativo, submetida à ação de inoculantes e ao efeito de emurchecimento. Revista Brasileira de Zootecnia, v.26, n.4, p.651-658, 1997.

BORGES, A.L.C.C.; GONÇALVES, L.C., RODRIGUEZ, S.M. et al. Silagem de sorgo de porte alto com diferentes teores de tanino e umidade no colmo. I. Teores de matéria seca, pH e ácidos graxos durante a fermentação. Arquivo Brasileiro de Medicina Veterinária e Zootecnia, v.49, n.6, p.719-732, 1997.

BRITO, A.F.; GONÇALVES, L.C.; RODRIGUES, J.A.S. et al. Qualidade das silagens de sete genótipos de sorgo e seus padrões de fermentação. In: REUNIÃO ANUAL DA SOCIEDADE BRASILEIRA DE ZOOTECNIA, 35., 1998, Botucatu. Anais... Botucatu: Sociedade Brasileira de Zootecnia, 1998. p.690-692.

DANLEY, M.M.; VETTER, R.L. Change in carbohydrate and nitrogen fraction and digestibility of forages: maturity and ensiling. Journal of Animal Science, v.37, n.4, p.994-999, 1973.

EICHELBERGER, L.; SIEWERDT, L.; SILVEIRA JR., P. Efeitos da inclusão de níveis crescentes de forragem de soja e uso de inoculante na qualidade da silagem de milho. Revista Brasileira de Zootecnia, v.26, n.5, p.867-874,1997.

GUIM, A. Estabilidade aeróbica de silagens de capim elefante (Pennisetum purpureum, Schum) emurchecido e tratado com inoculante microbiano. Jaboticabal: Universidade Estadual Paulista, 1997. 86p. Tese (Doutorado em Zootecnia) - Universidade Estadual Paulista, 1997.

GUTIERREZ, L.E.; FARIA, V. P. Influência da intensidade do murchamento sobre o teor de carboidratos solúveis do capim elefante (Pennisetum purpureum, Schum). O Solo, n.2, p.26-31, 1976.

ÍTAVO, L.C.V.; SANTOS, G.T.; JOBIM, C.C. et al. Efeito de aditivos nos parâmetros fermentativos da silagem de bagaço de laranja. In: REUNIÃO DA SOCIEDADE BRASILEIRA DE ZOOTECNIA, 35., 1998, Botucatu. Anais... Botucatu: Sociedade Brasileira de Zootecnia, 1998. p.385-387.

JONES, G.M.; DONEFER, E.; SAVED, A. et al. Intake digestibility by sheep of wilted alfafa timothy or corn silages ensiled at low and high dry matter levels. Journal of Animal Science, v.36, n.6, p.1315-1320, 1971.

LAVEZZO, W. Silagem de capim-elefante. Informe Agropecuário, v.11, n.132, 1985.

LIMA, M.A.; FERNANDES, A.P.M.; SILVA, M.A. et al. Avaliação de forragens nativas e cultivadas em área de caatinga no sertão de Pernambuco. Revista Brasileira de Zootecnia, v.16, n.6, p.517-531, 1987.

LÓPEZ, S.E.; MÜHLBACH, P.R.F. Efeito de diferentes tratamentos na composição químico-bromatológica da aveia branca (Avena sativa L.) conservada nas formas de silagem ou feno. Revista Brasileira de Zootecnia, v.20, n.4, p.333-338, 1991.

McDONALD, P. The biochemistry of silage. Chichester: John Wiley \& Sons, 1981. 228p.
MORAIS, M.G.; ROCHA JR., V.R.; GONÇALVES, L.C. et al. Grau de fermentação in vitro da matéria seca e teores de carboidratos solúveis da soja perene (Neonotonia wightii) cv. Tinaroo. In: REUNIÃO DA SOCIEDADE BRASILEIRA DE ZOOTECNIA, 35., 1998, Botucatu. Anais... Botucatu: Sociedade Brasileira de Zootecnia, 1998. p.699-701.

OBEID, J.A.; PEREIRA, J.C.; ANDRADE, M.A.S. et al. Produção forrageira e qualidade das silagens de milho consorciado com leguminosas. In: REUNIÃO DA SOCIEDADE BRASILEIRA DE ZOOTECNIA, 23., 1986, Campo Grande. Anais... Campo Grande: Sociedade Brasileira de Zootecnia, 1986. p.220.

PLAYNE, M.J.; McDONALD, P. The buffering constituints of herbace and silage. Journal of the Science of Food and Agriculture, n.17, p.264-268, 1966.

PRESTON, T.R. Better utilization of crop resitues and by-products in animal feeding: research guidelines - 2. A pratical maunal for research workers. Rome: FAO, 1986. 154p.

RANGRAB, L.H.; MÜHLBACH, P.R.F.; BERTO, J.L. Silagem de alfafa colhida no início do florescimento e submetida ao emurchecimento e à ação de aditivos biológicos. Revista Brasileira de Zootecnia, v.29, n.2, p.349-356, 2000.

SILVA, D.J. Análise de alimentos: métodos químicos e biológicos. 2.ed. Viçosa, MG: Universidade Federal de Viçosa, 1990. 165p.

SILVEIRA, A.C. Produção e utilização de silagens. In: SEMANA DE ZOOTECNIA, 2., 1988, Campinas. Anais... Campinas: Fundação Cargill, 1988. p.119-134.

TAYAROL MARTIN, L.C.T. Bovinos: volumosos suplementares. São Paulo: Nobel, 1997. p.82-138.

TOSI, H.; FARIA, V.P.; SILVEIRA, A.C. et al. Avaliação de leguminosas forrageiras de origem tropical como plantas para ensilagem. Pesquisa Agropecuária Brasileira, p.19-22, 1975. (Série Zootécnica, 10)

TOSI, P.; MATTOS, W.R.S.; TOSI, H. et al. Avaliação do capim elefante (Pennisetum purpurem Schum.) cultivar Taiwan A-148, ensilado com diferentes técnicas de redução de umidade. Revista Brasileira de Zootecnia, v.28, n.5, p.947-954, 1999.

UNIVERSIDADE FEDERAL DE VIÇOSA - UFV. SAEG Sistema de análises estatísticas e genéticas. Versão 2.1. Viçosa, MG: 1997. 150 p. (Manual do usuário).

WILKINSON, J.M. Additives for ensiled temperature forage crops. In: REUNIÃO ANUAL DA SOCIEDADE BRASILEIRA DE ZOOTECNIA, 35., 1998, Botucatu. Anais... Botucatu: Sociedade Brasileira de Zootecnia, 1998. p.73-108. 